\title{
Skeletal Anomalies and Congénital Heart Defect: A Report of Two Cases Observed in Pediatrics Department of University Hospital Centre of Brazzaville, Congo
}

\author{
Nika Evrard Romaric ${ }^{1 *}$, Mpemba Loufoua Anne Berthe ${ }^{2}$, Oko Aymar ${ }^{3}$ and Mabiala Babela Jean \\ Robert $^{3}$ \\ ${ }^{1}$ Department of Pediatrics, University Hospital Center of Brazzaville, Republic of Congo \\ ${ }^{2}$ Service de pediatrie Chu de Brazzaville, BP 32, Republique du Congo, Congo-Brazzaville \\ ${ }^{3}$ Facility of Health Sciences, Marien Ngouabi University, Brazzaville, Congo \\ *Corresponding author: Nika Evrard Romaric, Department of Pediatrics, University Hospital Center of Brazzaville, Republic of \\ Congo
}

\section{ARTICLE INFO}

Received: 幽 August 25, 2021

Published: 慧 September 08, 2021

\section{ABSTRACT}

Citation: Nika Evrard Romaric, Mpemba Loufoua Anne Berthe, Oko Aymar, Mabiala Babela Jean Robert. Skeletal Anomalies and Congénital Heart Defect: A Report of Two Cases Observed in Pediatrics Department of University Hospital Centre of Brazzaville, Congo. Biomed J Sci \& Tech Res 38(4)-2021. BJSTR. MS.ID.006188.

\section{Introduction}

Certain congenital heart defects such as, Tetralogy of Fallot, ductus arteriosus, pulmonary stenosis, atrio ventricular septal defect and truncus arteriosus, are often associated with extracardiac abnormalities [1]. We report two cases of congenital heart defect associated with skeletal anomalies observed in the department of pediatrics.

\section{Observation 1}

A 14-year-old girl admitted for an orthopnea. The History taking revealed a denial of paternity from a non-con-sanguineous marriage, a postnatal history of neonatal resuscitation; a school delay, and a family history of heart disease not identified (her uncle, and grandmother).Physical examination noted a cyanosis, a turgescent jugular veins, a postaxial hexadactyly of all four limbs (Figures $1 \& 2$ ), bilateral chronic pitting edema of legs, hepatomegaly with a liver size of $14 \mathrm{~cm}$ at percussion through midclavicular line, painful lower margin, and hepato jugular reflux. Heart auscultation, noted a tachycardia with $144 \mathrm{bpm}$, a gallop rhythm, a strong S1 at the apex with splitting of S2, a systolic murmur grade 2 at the upper left sternal border, apical systolic murmur grade 4 transmitting well to the left axilla. The Blood pressure level was $80 / 60 \mathrm{~mm} \mathrm{Hg}$ on both arms. The pulmonary auscultation was normal. The patient's pubertal development was stage 1 for breast development, and stage 1 for the development of external genitalia with a weight of $23.5 \mathrm{Kg}(<-3 \mathrm{SD})$ and the height of $140 \mathrm{~cm} \mathrm{(-3} \mathrm{SD),} \mathrm{the} \mathrm{BMI} \mathrm{was}$ estimated at 11.98 (<-3 SD).The cardiac ultrasound performed revealed an atrial septum absent with no venous anomalies, right ventricular dilatation, high grade tricuspid regurgitation, dysplastic mitral valve with shorten ropes, a coaptation defect leading to severe mitral regurgitation. The diagnostic was single atrium with severe mitral regurgitation. The chest Radiography revealed a cardiomegaly with cardiothoracic ratio at $80 \%$ (Figure 3 ) and increased vascular flow. The electrocardiogram showed a sinus rhythm at $125 / \mathrm{min}$, an axis at $+30^{\circ}$, incomplete right bundle branch block, biatrial enlargement, and right ventricular hypertrophy (Figure 4). Hands radiography showed (Figure 5): 
a hexadactyly with fifth T-shaped metatarsal of the right hand associated to the fifth Y-shaped metacarpal of the left hand, both articulating with two well-formed phalanges. Concerning feet, a hexadactyly, with fifth T-shaped metatarsal, ending in well-formed toes; were found. Thus, the association between the weight loss, the pubertal delay, a hexadactyly and a single atrium with heart failure could be part of an Ellis Van Creveld syndrome. The patient was treated with digoxin, diuretics and angiotensin--converting enzyme (ACE) inhibitor that improved her condition and justified her discharge. She died six months later because of a heart failure.

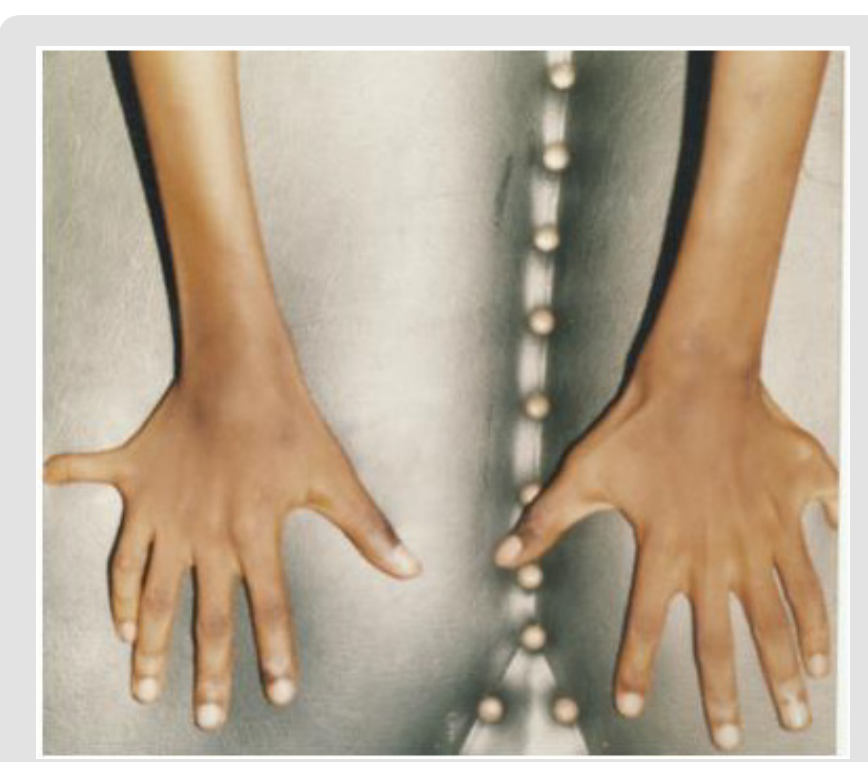

Figure 1.

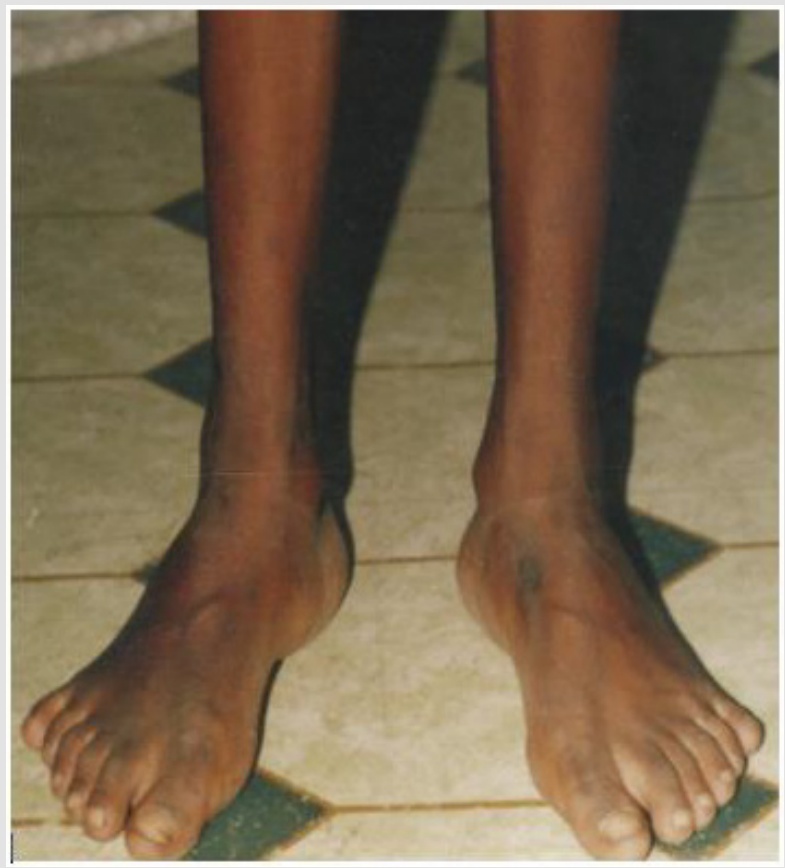

Figure 2.

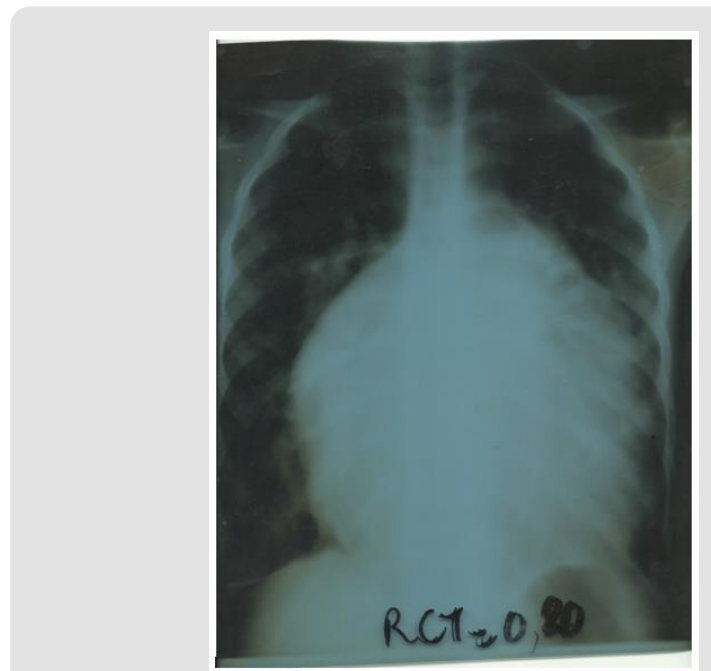

Figure 3.

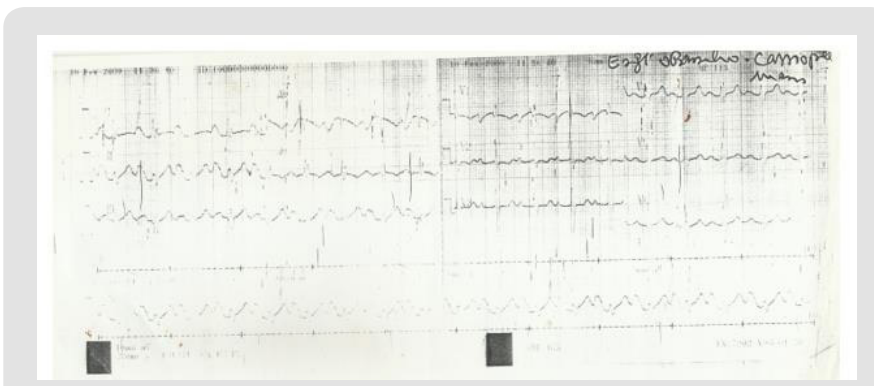

Figure 4.

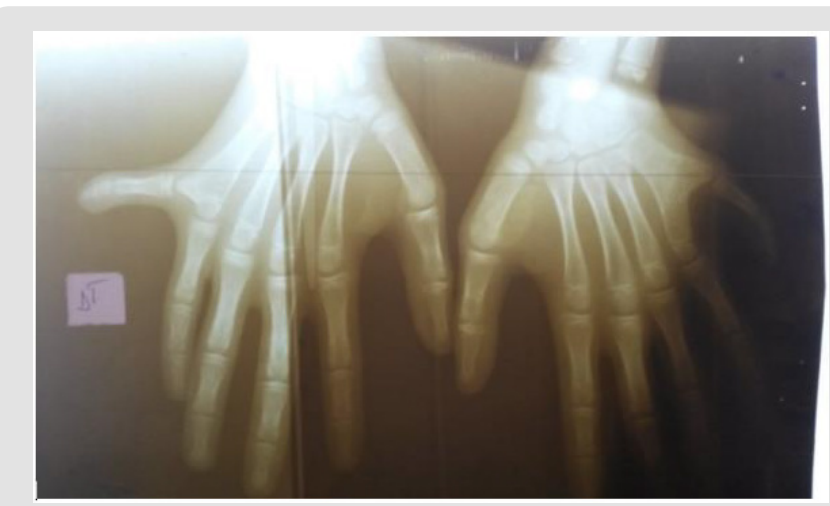

Figure 5.

\section{Observation 2}

A one-month-old female infant admitted for a heart murmur. The history taking revealed a neonatal history of birth asphyxia, leading to hospitalization. A family history of polydactyly was noted, the father and the aunt, especially (Figure 6). There was no notion of consanguinity in the parental couple. Physical examination showed an eutrophic infant with $3.5 \mathrm{~kg}$ for $50 \mathrm{~cm}$, a pre and post axial hexadactyly was observed in the upper limbs (Figure 7) and lower limbs (Figure 8 \& Figure 9), a hexadactyly with syndactyly. 
Heart auscultation found a systolic murmur grade 4 at the fourth left intercostal space transmitting to the precordium. The heart rate was $100 \mathrm{bpm}$. Echocardiography revealed the presence of membranous ventricular septal defect of $5.8 \mathrm{~mm}$ in diameter, with a left to right shunt, a paradoxical inter ventricular septum motion, parietal hypertrophy without enlargement of the cavities. On Chest radiography, a cardiomegaly with a cardiothoracic ratio of $66 \%$. Therefore, she presented a poly syndactyly and a ventriculoseptal defect suggestive of Ellis Van Creveld syndrome. Six (6) years, later, she had grown, her height was $105 \mathrm{~cm}$ (-2 SD), and her weight $17.500 \mathrm{Kg}$ (-1DS). Heart auscultation was normal, and Echocardiography showed a closed ventricular septal defect.

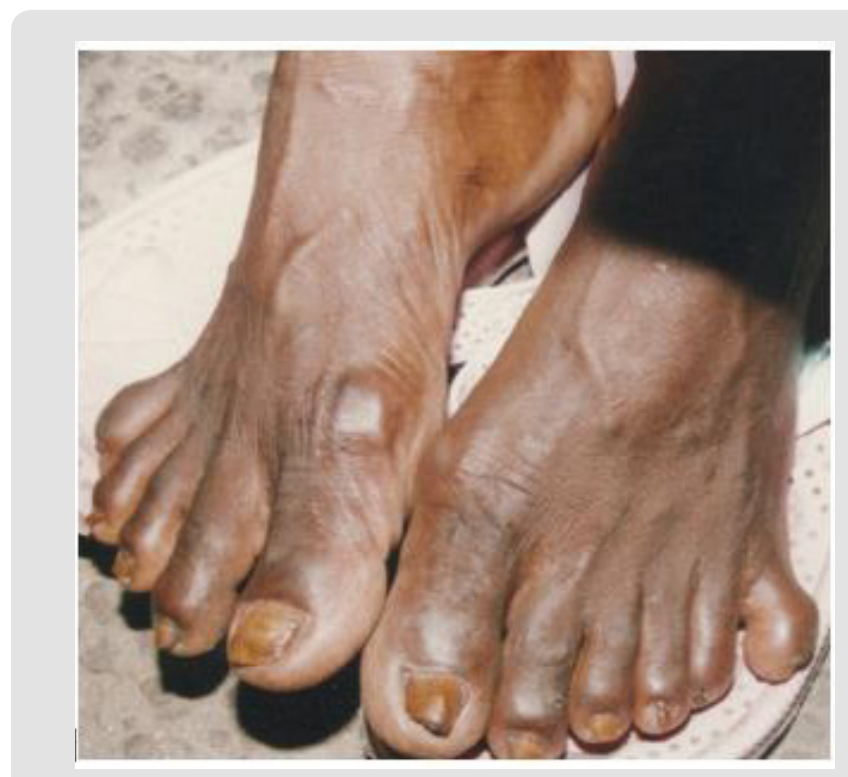

Figure 6.

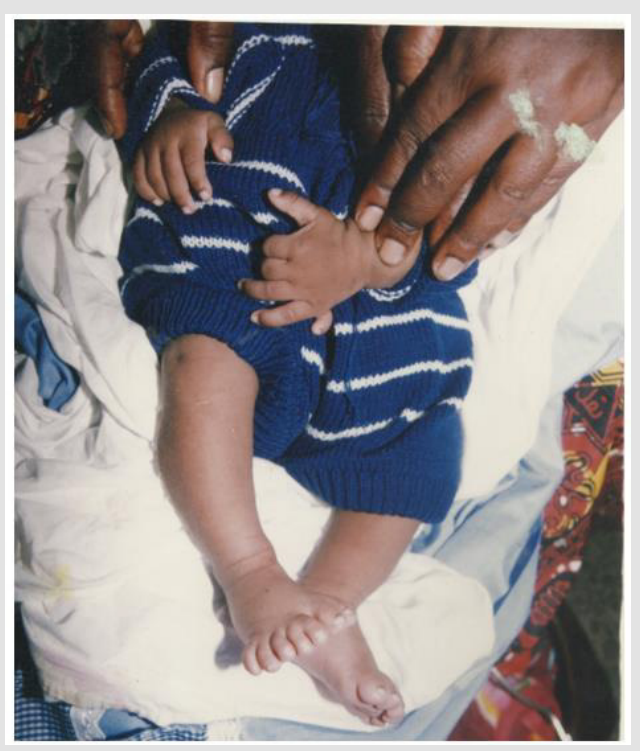

Figure 7.
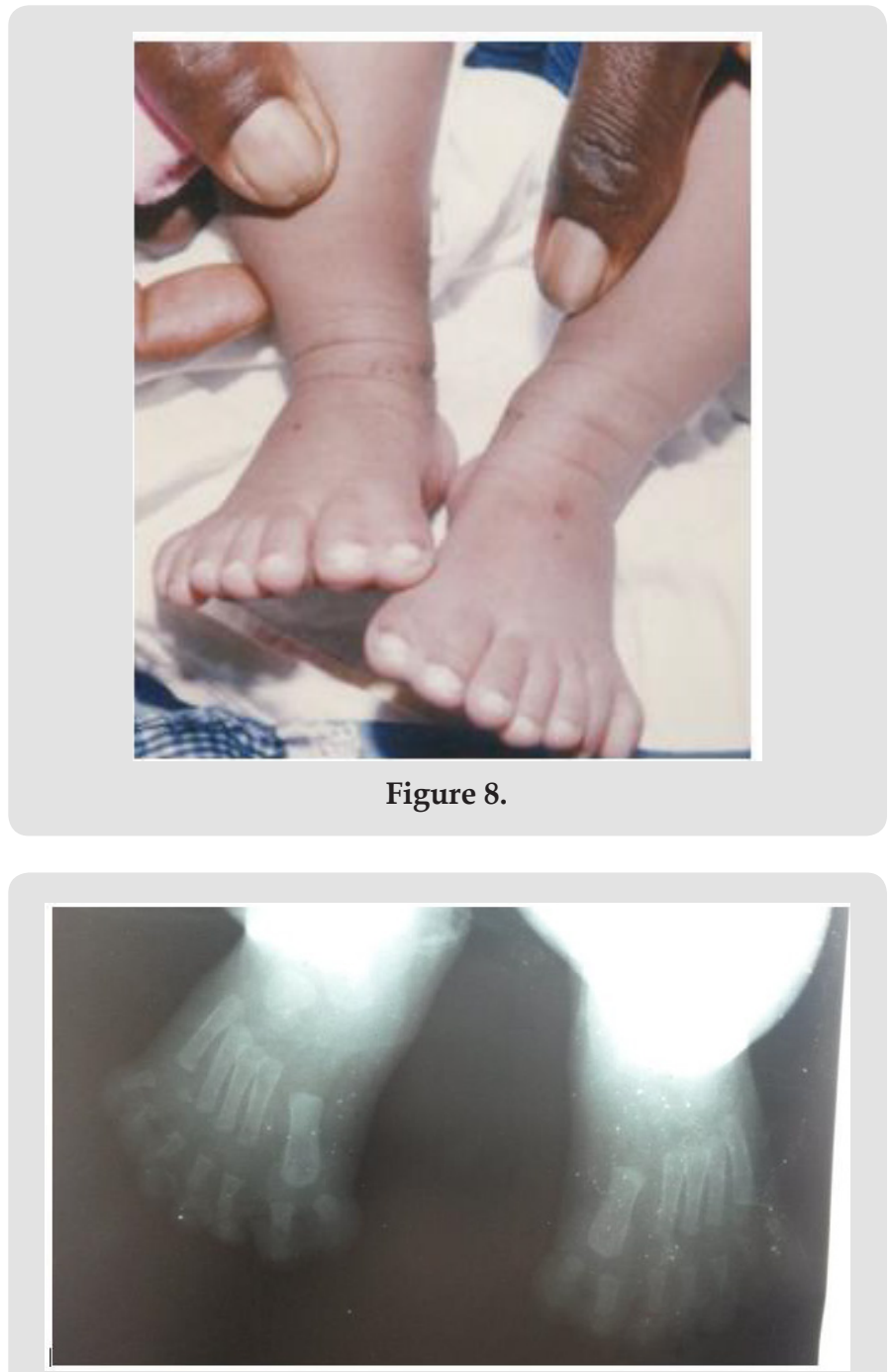

Figure 9.

\section{Discussion}

The association between congenital heart disease and upper limb abnormalities is common [2]. However, in Congo, few cases have been observed in Pediatric ward. Of 1500 children received by a pediatric cardiologist, these last five years, three (3) only presented skeletal anomalies associated with congenital heart defect. The first patient presented a Holt-Oram syndrome [3], and the last two were the subjects of our report. A large number of syndromes have been reported and classified as heart-hand desorders". These cardio-skeletal syndrome suggest that some of the genes involved in these syndromes have ubiquitous actions or affect early developmental pathways that comprise a regulatory cascade in cardiac and skeletal morphogenesis [2]. However, certain syndromes are uncommon such as the syndrome of Ellis Van Creveld observed in our patients. Indeed, Ellis Van Creveld syndrome or chondro-ectodermal dysplasia described in 1940 by Richard Ellis and Simon Van Creveld is an uncommon genetic 
disorder that affects bones growth [4,5]. A Hereditary disease with autosomal recessive transmission resulting from a mutation of the EVC1 and EVC2 genes located on chromosome 4p16 [6,7]. This syndrome affects both sexes even though the report is about two females. The highest frequency of this syndrome is observed in the Amish population of Lancaster in the United States, 2 per 1000 $[4,5]$. The worldwide incidence of that disorder is $1 / 244000$ births with approximately 150 cases reported $[5,6,8]$. It is a chondroectodermal dysplasia which associates endochondral growth disorders, polydactyly ectodermal abnormalities, and heart defects observed in 50 to $60 \%$ of cases for some authors, and $25 \%$ of Cases for others [9]. Heart defects are determinant for the prognosis. Our two patients had heart defects (single auricle, ventriculoseptal defect) which prompted the consultation (heart failure for the first, heart murmur for the second). Atrial septation abnormalities are observed in $60 \%$ of cases [6].

In fact, the first patient had an absence of inter-auricular septum. This exceptional malformation commonly associated with the syndrome of Ellis Van Creveld;[1] is an ostium primum without inter-auricular partition. Other cardiac malformations have been described such as ductus arteriosus, atrial septal defect or ventricular septal defect [10], hypoplastic left heart syndrome, atrial ventricular septal defect $[5,7]$. Chakraborty and al. reported the observation of a triatrial heart, an uncommon congenital heart defect in a 9-year-old patient with Ellis Van Creveld syndrome [11]. Our second patient presented a ventricular septal defect as the one reported by Thapa et al. [5]. As pointed out by Bonnet and Bouvagnet [2], mutations in the same gene can have a spectrum of heart phenotypes without direct embryological link. A polydactyly of four limbs was observed in our two cases as reported by Shetty et al. [12]. The polydactyly mostly observed is the post axial hexadactyly of upper limbs [5]. Different types of polydactylies have been described such as malformed supernumerary digits located on the ulnar side like our first patient contrary to the second who pre axial polysyndactyly of lower limbs (well-formed supernumerary toes with syndactyly from the big toe). The micromelia commonly described was not observed in our two observations, nor did the fingernail dysplasia [13]. However, a fingernail dysplasia was noticed to the aunt of our second patient (Figure 6).

The hair was normal in appearance. Our patients did not have the typical lips, teeth and nails of Ellis Van Crefeld syndrome as described by Ulucan and al. [14]. Nevertheless, they had single atrium and polydactyly for the first, and ventricular septal defect with polydactyly for the second. In their series, Ulucan and al., demonstrated the presence of 2 novel heterozygous EVC mutations c.15_16ins46bp and c.1864C1T, p. Arg622X, predicted to cause a loss of function in both alleles, which was homozygous in the affected individuals and concluded that this EVC mutation is hypomorphic and can lead to heart and limbs anomalies less severe than the typical form of EVC. Would it be the case in our patients? Zhang $\mathrm{Z}$ and al. [15]. identified a new mutation of the EVC2 gene in a young Chinese man with an Ellis Van Creveld syndrome. A large variability of the clinical manifestations is frequently observed [5]. The common description includes chondrodystrophy, polydactyly, ectodermal dysplasia, and congenital heart defect. These different features were observed in our two patients. The molecular analysis could have been of great interest to support the diagnosis [16,17], but not available in our country. Some authors reported that Cognitive and motor development are normal [6,7]. However, a school delay has been noted with our first patient possibly related to her state of health. This disease can be recognized as early as the antenatal period (eighteenth week of gestation). In fact, Chen chih ping and al. [18]. state that prenatal diagnosis is possible, and suspicion of bone dysplasia is possible thanks to fetal biometry and cardiac malformations with polydactyly. Otherwise from birth, because polydactyly cannot go unnoticed which was the case for our second patient.

The outcome is variable, patients who survive have usually less severe short stature than those with achondroplasia.in fact, the first patient had a short stature at -3DS, and the second at - 2DS. In the same way, the existence of large variations are described in the literature with an adult height ranging from 135 to $140 \mathrm{~cm}[5,13]$. The management of these syndromes must be multidisciplinary (management during the neonatal period, treatment of respiratory distress due to chest or cardiac disorder, orthopedic and / or dental care). The prognosis is related to the severity of heart defect and the respiratory disorder. Our first patient died of heart failure. Indeed, close to $50 \%$ of individuals with chondroectodermal dysplasia die in infancy after cardiorespiratory complications [12,19], however, adult patients with Ellis Van Creveld syndrome with congenital heart defect have already been reported [10].

\section{Conclusion}

Skeletal anomalies can be part of a poly malformative syndrome associating cardiac anomalies as well. Their discovery must lead to a close examination to look for malformations associated in particular heart disorder which determine the prognosis in the short and medium term, consequently the echocardiography is necessary.

\section{References}

1. Batisse A, Fermont L, Lévy M (2013) Pediatric Cardiology practice. Doin pp. 330.

2. Bonnet $D$, Bouvagnet $P(2001)$ cardiac development genes and congenital heart defects. Médecine et thérapeutique 4: 278-283.

3. M pemba Loufoua-Lemay AB, Holt-Oram Syndrome (2015) A report of a case at university Hospital Center. Ann Afr Med 8(3): 2077-2081. 
4. Kurian K, Shanmugam S, Harsh Vardah T, Gupta S (2007) Chondroectodermal dysplasia (Ellis Van Creveld syndrome): a report of three cases with review of literature. Indian J Dent Res 18(1): 31-34.

5. Thapa R, Mukhopadhyay M, Bhattacharya A (2008) Discordance for Ellis-van Creveld syndrome in twins. Singapore Med J 49(12): 369-371.

6. Baujat G, Le Merrer M (2007) Ellis Van Creveld syndrome. Orphanet Journal of rare Diseases (2): 27.

7. Lichiardopo IC, Militaru C (2006) Ellis van Creveld syndrome. Rom Morphol Embryol, 2006; 47(4): 363-366.

8. Alves -Preira D, Berini-Aytès L, Gay-Escoda C (2009) Ellis -van Creveld syndrome. Case report and literature review. Med Oral Cir Bucal 14(7): 340-343.

9. Bouguerra L, Turki R, Hichri A (1995) Echocardiography interest in the diagnosis of Ellis Van Creveld syndrome. Arch Pédiatr 2(10): 1022.

10. Katsouras CS, Thomadakis C, Michalis LK (2003) Cardiac Ellis van Creveld syndrome. International Jounal of Cardiology 87(2-3): 315-316

11. Chakraborty PP, Bandyopadhyay D, Mandal SK, Subhasis RC (2007) A rare variant of Ellis- van Ceveld syndrome. Singapore Med J 48(7): 684686.

12. Shetty P, Shetty D, Priyadarshina PS, Bhat S (2015) A rare case report of Ellis Van Creveld syndrome in an Indian patient and literature review. Journal of oral biology and craniofacial research 5(2): 98-101.

\section{ISSN: 2574-1241}

DOI: 10.26717/BJSTR.2021.38.006188

Nika Evrard Romaric. Biomed J Sci \& Tech Res

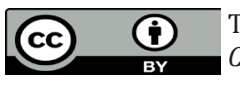

This work is licensed under Creative Commons Attribution 4.0 License

Submission Link: https://biomedres.us/submit-manuscript.php
13. Maroteaux P (1982) Osteochondrodysplasias in Bone diseases of children. Flammarion Médecine-Sciences 64-67.

14. Ulucan H, Sadd JC, Cockerham J, Johnston JJ, Biesecker LC, et al. (2007) Extending the spectrum of Ellis Van Crefeld syndrome a large family with a mild mutation in the EVC gene. BMC Med Genet 8(9): 92.

15. Zhang Z, Bao K, He w, Zhang C, Zhang Z, et al. (2012) Identification of one novel mutation in the EVC2 gene in a Chinese family with Ellis-Van Creveld syndrome. Gene 511(2): 380-382.

16. Van Hagen JM, Baart JA, Gille JJ (2005) From gene to disease; EVC, EVC2, and Ellis- Van Creveld syndrome. Ned Tijdschr Geneeskd 149(17): 929931.

17. Howard TD, Guttmacher AE, Mckinnon W, Sharma M, Mckusick VA, et al. (1997) Autosomal dominant postaxial polydactyly, nail dystrophy, and dental abnormalities map to chromosome 4P16, in region containing the Ellis- Van Creveld syndrome locus. Am J Hum Genet 61(6): 1405-1412.

18. Chen CP, Su YN, Hsu CY, Chern S, Tsai FJ, et al. (2010) Ellis-Van Creveld syndrome: prenatal diagnosis, molecular analysis and genetic counseling. Taiwan Obstet Gynecol 49(4): 481-485.

19. Dugoff L, Thieme G, Hobbins J C (2000) Skeletal anomalies. Clinics in perinatology (27) 4: 979-1005.

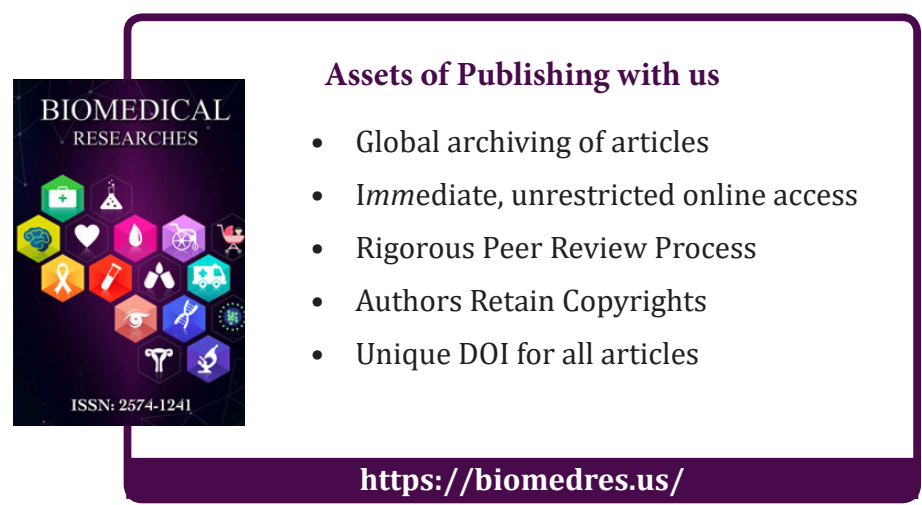

